\title{
Reform and Practice of Talents Cultivation Mode for Civil Engineering
}

\author{
Zhenhua Liu ${ }^{a_{*}}$, Ying Cui ${ }^{b}$, Yumin Zhang $^{c}$, Jianbo Dai ${ }^{d}$ and Xiyu Zhu ${ }^{e}$ \\ Mechanical Engineering College, Xi'an Shiyou University, Xi'an, 710065, China \\ aliuzhenhua@xsyu.edu.cn, ${ }^{b} 48938895 @ q q . c o m$, ${ }^{c} 35813930 @ q q . c o m,{ }^{d} d$ _jianbo@foxmail.com, \\ 375209240@qq.com
}

\section{Keywords: CDIO; Talents Cultivation mode; Civil Engineering; Practical Ability}

\begin{abstract}
Based on the law of civil engineering teaching and the training goal of high quality engineering and technical graduate, the cultivation mode of civil engineering program based on CDIO engineering education concept is constructed. The teaching mode was reformed in personnel training programs, curriculum teaching, graduation design, and so on. A cultivation mode that integrates knowledge, ability and quality together was built. It can provide a reference for the reform of cultivation mode of engineering and technical talents.
\end{abstract}

\section{Introduction}

In 2010, Chinese Ministry of Education proposed the "Excellence Engineer education program". It aims to cultivate a large number of high quality technical graduate who have strong innovative ability, and adapt to the needs of economic and social development [1]. However, in our university, the civil engineering has been built in a relatively short time, the problems of students' practical ability and innovation ability are insufficient. The graduates are hard to adapt the social demand. Therefore, it is urgent to improve engineering education mode in order to adapt to the needs of personnel training.

Now, there are various ideas and modes of education. One of much effective is the engineering education mode named as CDIO (Conceive, Design, Implement, and Operate) [2-4]. Its basic idea is for modern engineers to lead a modern industrial product, process or system development. The engineers must possess knowledge, ability and quality simultaneously. They regard modern engineering practice as the background environment. The training curriculum of both mutual connection and mutual support system were used during teaching. Then this manner can give students rich design experience and active learning experience in modern learning and practice environment. It also promotes the students' knowledge, ability and quality of the growth of the integration [1]. Currently, there are dozens of colleges and universities carried out the practice of CDIO teaching the reform. Satisfied effects were achieved up to now [5-7].

\section{The Construction Strategy of CDIO Talents Cultivation Mode}

The implementation of CDIO personnel cultivation mode is a systematic project. A complete operation of the CDIO needs to develop a new four year undergraduate program, to revise various documents for the target [8-9], to cultivate the ability that includs a series files up to more than 400 refinement items. In order to reach all these objectives, a lot of work and financial resources were needed. Also, there must be active cooperation with relevant departments. Otherwise, the real implementation of CDIO engineering education will encounter many problems and difficulties [10-11]. However, the concepts of CDIO engineering education have a strong guiding significance in the positioning of the teaching reform and implementation for civil engineering. In the conditions of limited human and financial resources, we focus on the main problems in the civil engineering for the personnel training and introduce the ideas of CDIO engineering education but not copy the CDIO mode completely to the construction of cultivation mode.

The training program of civil engineering is divided into two categories: theoretical teaching system and practice teaching system; but the most prominent problem is the theory course teaching. Since 
teachers pay more attention to teach more knowledge, also hope their students can grasp more knowledge. For this purpose, homework is also used to train students to understand the concepts that were usually used to enhance the application of theoretical knowledge and problem-solving ability. In general, the basic requirements of curriculums can be achieved for students to learn the knowledge; but the requirements on ability and training are not enough. After learning these courses one by one, students' knowledge is accumulating, but the effective methods are lack for the ability training. In a long period, students pay attention to knowledge accumulation, to do a lot of exercises. However, due to the lack of theoretical application in the actual engineering practice ability, their practice ability dose not be improved simultaneously. More don't be talked about innovation ability.

Therefore, in order to improve the practice ability and innovation ability for undergraduate of civil engineering, in addition to experiment and practice teaching reform, it is important to pay more attention to the reform of the theory teaching and the mode of graduation design. Especially, the theory curriculum dominates the training program. It is the key factors in personnel training. One of the reason of neglecting ability training is the lack of effective implementation in teaching. The introduction of CDIO education style lets the ability training is able to implement.

\section{Constructing the Talents Cultivation Mode of Civil Engineering Based on CDIO Concepts}

According to the CDIO's philosophy of education teaching, students' ability must be paid more attention during the course teaching. Therefore, in the processes of lessons preparing and teaching, we carry out such idea as "not only imparting knowledge but cultivating students' comprehensive ability". Heuristic and discussing teaching modes were used to cause the students' positive and independent thinking. For some examples, teachers try to found practical engineering prototypes. Then, with the help of teaching aids, pictures or video, every class was taught according the following steps such as the problem analysis, model simplification, problem solution and discussion. This process regards a real problem as a reference. It not only improves the students' interest in learning effectively, but also strengthens students' perception of the actual project, finally enhances the ability to solve practical engineering problems.

In CDIO education, the environment and opportunities ought to be constructed for students to obtain knowledge initiatively. At present, the main way for students to learn is to do simulation exercises. In order to increase the opportunity of practice for students and to have a good foundation to prepare to participate in the following whole CDIO process, we design the extracurricular practice homework in courses. The homework comes from the real and practical engineering problems. These problems are the prototype of the present homework. Students may complete this homework by observation, analysis, judgment, calculation, discussion and other aspects. The present way of "experience the whole process of problem-solving training" changes the learning style that students only do simulation exercises. It also improves the ability of solving practical problems. Students gradually transfer from only doing simulation exercises to enable to solve practical problems.

In the process of graduation design, students are demanded to undergo the "Conceive" and "Design" of CDIO. Due to the limitation of teaching conditions, the "Implement" and "Operate" of CDIO cannot be truly achieved yet. However, some realistic design topics were introduced. Thus, students not only can fully understand the actual design work requirements and strengthen practice ability, but also understand the implementation of the "Implement" and "Operate" of CDIO.

\section{The Effect of Teaching Reform}

The ability training objectives were refined according to the new teaching syllabus. The new definition of the ability target, which was ignored previously, was given, implemented and enhanced now. Teachers can introduce a certain amount of the real problems or the practical engineering problems with the help of multimedia technology in order to construct the active learning environment and the engineering background for students.

After the teaching reform of CDIO courses, students not only enable to grasp the basic theoretical knowledge of the course syllabus satisfied, but also enhance the abilities of both analyzing and solving problems. Furthermore, other abilities such as obtaining new knowledge, practice and cooperation, were 
enhanced simultaneously. Thus, the teaching processes cultivate the students as the engineer's sense of mission and responsibility; so that the quality of teaching is improved.

During the present reformation performing, some practical engineering problems, which were related to the curriculum theory, were increased as routine homework. They were helpful for students to obtain the opportunity of contacting the real engineering problems. The perceptual knowledge was increased from the complete problem-solving process for students. Students can understand the theory and curriculum knowledge correctly, obtain the upgrade of multi abilities, and change the single mode of learning and rigid mode of thinking. The present teaching mode also stimulates the students' interest in learning, improves students' learning initiative. Students can find problems in practice; improve the sense of innovation in solving problems. Thus, they have more expectations for increasing the opportunity of practice.

In the reform process of graduation design, real engineering design problems were introduced; so that the graduation design become more practical. Compared with the traditional way, students get a more comprehensive training. It is conducive to the cultivation of students' overall engineering concepts and the grasping for overall design work. Totally, students' engineering ability, communication skills, analysis problems and problem-solving ability can be improved. They also lay a good foundation for students to adapt to the work quickly after graduation.

The feedback from students indicates that they approved the new learning mode. Most of them have a higher interest in the course learning and learn more. They hope to get more practice. In the class teaching time, it is not only necessary to strengthen the students' practical ability, innovation awareness; but also expand the depth and breadth for curriculum content. However, some students feel the amount of information was so large and the progress was so fast. Sometimes it is difficulty to keep up with the schedule. For these problems, teachers need to adjust their teaching mode properly according to the student's acceptation ability in order to achieve the desired results.

\section{Conclusions}

According to the professional characteristics of the civil engineering, the cultivation mode of students was constructed based on the concept of CDIO. By the several aspects of reforming such as classroom teaching methods, the style of learning, the way of graduation design, the students' interest in learning was improved effectively.

The present teaching reform makes the students have a strong self-learning ability, problem-solving ability and innovation consciousness. It promotes the students' integrated growth for knowledge, ability and quality.

The reform and practice of the cultivation mode laid a solid foundation for the subsequent development of students. It has certain reference significance for the construction of CDIO education mode in other specialized fields as well.

\section{Acknowledgements}

The authors are gratefully acknowledged for the financial support for this work by Shaanxi Higher Education Teaching Reform Research Project (project number: 15BY55) and Xi'an Petroleum University Teaching Reform Research Project (project number: 0309-131010390).

\section{References}

[1] J. Lin. Development of General Standard for Excellence Engineer Education and Training Program. Research in Higher Education of Engineering, 2010 (4), p21-29. (In Chinese)

[2] P.H. Gu, X.H. Lu , G.J. Xiong, S.P. Li and M.F. Shen .Development of design directed engineering curriculum based on CDIO Framework, World Transaction on Engineering and Technology Education, Vol.5, 2006 (2), p21-25 .

[3] W.R. Chen, L.J. Ren, L. Zhang and F. Yang. Project reform of CDIO mode based on Singapore Institute of Technology.Vocational and Technical Education, 2009 (35), p91-93. (In Chinese) 
[4] F. Chen. Teaching Discussion on Modern Control Theory Course Based on CDIO Concept. Experiment Science and Technology, 2012 (3), p69-70. (In Chinese)

[5] Q.W. Lu, L. Cao, Y.N. Li and W.F. Chen. Based on CDIO mode training compound excellent software engineers to explore. Higher Education Exploration, 2013 (1), p71-76. (In Chinese)

[6] Q.L. Kang and F.J. Ding. A Retrospect and Reflection on the Reserch into the CDIO Engineering Education in China. Research in Higher Education of Engineering, 2016 (04), p40-46. (In Chinese)

[7] P.H. Gu and N.S. Bao. CDIO in China (1) . Research in Higher Education of Engineering, 2012 (3), p24-40. (In Chinese)

[8] Y.F. Tao and C.H. Shang. The Enlightenment of CDIO Syllabus on the Innovation of Higher Engineering Education. China Higher Education Research, 2006 (11), p81-83. (In Chinese)

[9] E. Crawley,J. Malmqvist,W. Lucas,D. Brodeur. The CDIO Syllabus v2.0 -An Updated Statement of Goals for Engineering Education. Proceedings of the 7th International CDIO Conference,Technical University of Denmark,Copenhagen,June 20-23,2011

[10] W.L. Hu. The development of engineering education in the era of innovation: challenge and response. Research in Higher Education of Engineering, 2016 (2), p32-33. (In Chinese)

[11] P.H. Gu, W.L. Hu, X.H. Lu, Q.S. Bao and P. Lin. From CDIO in China to China's CDIO: stady on development path, impact and its causes. Research in Higher Education of Engineering. 2017 (01), p24-43. (In Chinese) 